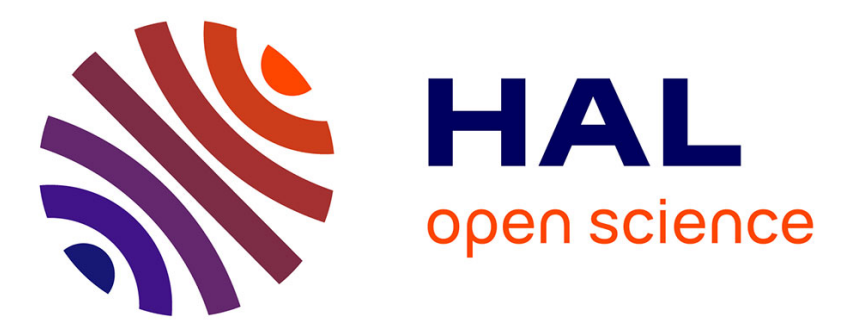

\title{
Damage Assessment of Spinal Bones Due to Prostate Cancer
}

Octavio Andrés González Estrada, Sergio Andrés Ardila Parra, Jabid Quiroga

\section{To cite this version:}

Octavio Andrés González Estrada, Sergio Andrés Ardila Parra, Jabid Quiroga. Damage Assessment of Spinal Bones Due to Prostate Cancer. Key Engineering Materials, 2018, 774, pp.149 - 154. 10.4028/www.scientific.net/KEM.774.149 . hal-01879051

\section{HAL Id: hal-01879051 \\ https://hal.science/hal-01879051}

Submitted on 21 Sep 2018

HAL is a multi-disciplinary open access archive for the deposit and dissemination of scientific research documents, whether they are published or not. The documents may come from teaching and research institutions in France or abroad, or from public or private research centers.
L'archive ouverte pluridisciplinaire HAL, est destinée au dépôt et à la diffusion de documents scientifiques de niveau recherche, publiés ou non, émanant des établissements d'enseignement et de recherche français ou étrangers, des laboratoires publics ou privés. 


\title{
Damage Assessment of Spinal Bones Due to Prostate Cancer
}

\author{
Sergio Andrés Ardila Parra ${ }^{1, a}$, Octavio Andrés González-Estrada ${ }^{2, b}$ \\ and Jabid Quiroga ${ }^{1, c}$ \\ ${ }^{1}$ GIEMA, School of Mechanical Engineering, Universidad Industrial de Santander, Ciudad \\ Universitaria, Bucaramanga, Colombia. \\ ${ }^{2}$ GIC, School of Mechanical Engineering, Universidad Industrial de Santander, Ciudad \\ Universitaria, Bucaramanga, Colombia. Orcid: 0000-0002-2778-3389. \\ asergio.ardila9@correo.uis.edu.co, bagonzale@uis.edu.co, cjabib@uis.edu.co
}

Keywords: bone damage, bone segmentation, spinal, metastasis, FEA.

\begin{abstract}
The present research proposes a methodology to determine the strength of a spinal bone in patients who suffer from prostate cancer using diagnostic imaging, with the purpose of verifying if metastasis has occurred, and critical conditions have been reached. Advanced numerical methods allow the modelling of anisotropic materials for different applications in biomedical engineering. The computed tomography images (CAT) provide the information to create a 3D model of the bone, in this case, the lumbar vertebra L5. Using segmentation software, it is possible to identify the mechanical properties of the materials that form the bone and define anisotropic conditions. The 3D anisotropic model is evaluated using finite element analysis (FEA), considering the appropriate boundary conditions and its respective material properties, and compared with the reference case of a healthy bone in an initial stage to assess the damage. Indicators based on the changes in stiffness of the vertebra could provide evidence of the need for chirurgical intervention.
\end{abstract}

\section{Introduction}

Personalized medicine is one of the greatest challenges of engineering, once tools have been developed to investigate the complexity of biological systems. Medical imaging (MI), e.g. Computerized Axial Tomography (CAT) and Magnetic Resonance Imaging (MRI), are important since they represent a clear basis to promote the development of personalized medicine, based on the profile of the individual and not on the disease [1], [2]. With MI, we can develop patient-specific models that allow realistic numerical simulations to obtain more information relative to the patient [3]-[6]. These patient-specific models can be used for the mechanical characterization of the bone structure and to estimate the damage in scenarios such as, for example, implants, osteoporosis or bone loss by metastasis [7], decreasing the risk of critical events for the patient, and allowing to schedule treatments or surgical interventions that seek to improve the quality of life of the patient.

As primary tumours are diagnosed earlier, the detection of metastasis becomes more important and more difficult [8]. Clinically, even in the presence of known spinal metastases, more than $1 / 3$ of the patients did not have back pain [9]. The principal cause of death is due to the spread of cancer to other sites. Patients with advanced breast and prostate cancers almost always develop bone metastases [10]. Current measurement techniques for bone metastases are not accurate and can be very expensive. Reports using bone scintigraphy (BS) show sensitives ranging between $62 \%$ and $89 \%$ [11], however, recent research shows accuracy less than 50\% [12]. Magnetic resonance imaging (MRI) is the most accurate technique to detect bone metastases, sensitive has been evaluated around 90\% [2], [7], [12]. Nevertheless, authors suggest the use of BS on the assumption that MRI would be costly, consumes a lot of time and would be clinically involved [13].

Three-dimensional models can provide a lot of useful information that helps clinicians to determinate 
the state of a bone or even an organ [6]. In the case of metastasis to vertebrae, based on stacks of sagittal, coronal and axial slices from a CAT, it is possible to obtain a 3D model of the bone structures using segmentation tools [3], [14]. Advances in software and hardware have made feasible to manipulate such data on personal computers [15]. Then, numerical methods can be used to detect changes in the bone and evaluate structural integrity [4], [5]. This methodology allows finding structural changes in the vertebrae after the diagnosis of prostate cancer. These models would provide information to assess the risk of collapse of the vertebrae, which would contribute to anticipate the use of treatments that reduce the risk of suffering invalidating complications caused by fractures.

In this work, we use the segmentation software Mimics $\odot$ to process the CAT image and generate the 3D model of a vertebra L5 affected by metastasis. Anisotropic material properties associated to the bone are extracted from the CAT data [16]. Then, a finite element analysis (FEA) was performed with the software Ansys $@$ to verify the mechanical response of the bone structure. The 3D finite element model can represent the irregular geometry and inhomogeneity of this tissue [17]. Physiological biomarkers are proposed to evaluate the risk of collapse of the vertebra as metastasis progresses.

\section{Methods}

Computed axial tomography images are used to build a 3D model, the stack of images collected are based on grey scale information (Hounsfield units). Two CATs of the L5 vertebra of a patient are analysed, corresponding to year 2009, with the healthy vertebra, and to year 2014, when the patient had developed, by metastasis, a lytic lesion. The segmentation is done for CAT images with a slice thickness of $2.50 \mathrm{~mm}$ and a slice increment of $2.00 \mathrm{~mm}$. The CAT data is imported into Mimics software, where geometrical details are defined and, then, meshed in 3-Matic to generate volumetric mesh, Fig. 1. The maximum triangle edge length used is $1 \mathrm{~mm}$, and flip threshold angle is 15 .

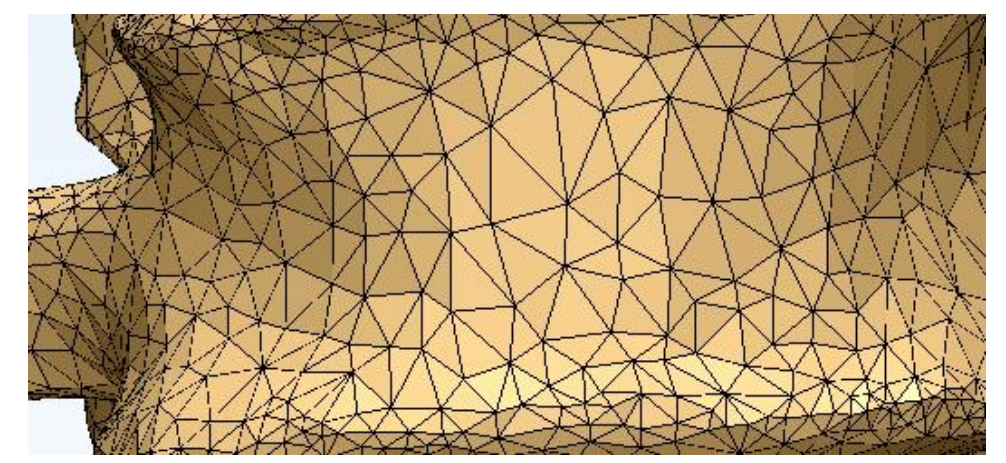

Figure 1. Sample of elements created with the parameters established for meshing.

The volumetric mesh is imported into Mimics to map anisotropic properties. The relationship between the Hounsfield value $H U$ and the material apparent density $\rho_{a p p}$ is assumed linear [16], the empirical expression reads:

$\rho_{a p p}=1.22 \cdot H U+47\left[\mathrm{~g} / \mathrm{cm}^{3}\right]$

An empirical expression is selected to assign an average Young modulus $E$ to each element, relating apparent density with elasticity modulus. Validation of different expressions was studied in previous literature [18]. The relation used in this work reads:

$E=0.63 \cdot \rho_{a p p}{ }^{1.35}[M P a]$

The resulting volumetric and surface meshes are imported into Ansys to define the finite element model, where boundary conditions were incorporated based on the load real conditions generated by 
typical human body movements. The boundary conditions used in the FEA have been determined from [19]. Lifting was the exercise taken as a reference to evaluate the different loads acting on the lumbar L5. A total of 5 loads, forces and moments, were used. One force, $F=[20 ; 1378 ; 405] N$, and one moment, $M=[6,4 ;-0,05 ;-1,3] N . m$, due to the interaction with the intervertebral disc of a ligamentous motion segment and the other three forces related to muscles, $F_{12}=84,85 N, F_{34}=$ $123 \mathrm{~N}$, as shown in Fig. 2. A static analysis is performed considering a fixed support in the lower zone of the bone. In structural health monitoring (SHM), a common indicator to assess damage is to evaluate changes in the eigenvalues and eigenvectors of the structure [20]. We propose to extract information from the stiffness matrix, trying to define biomarkers for bone damage.

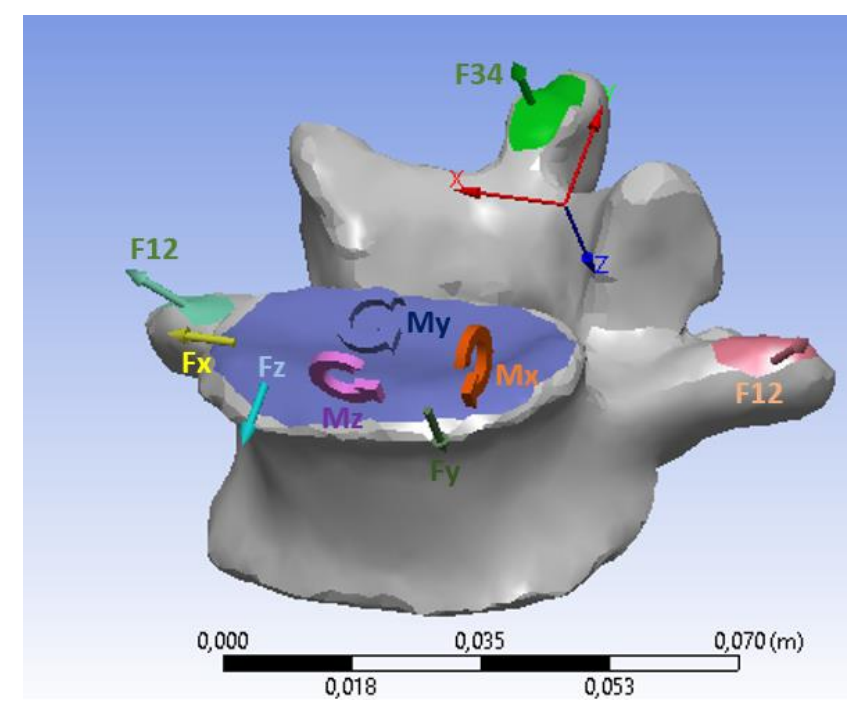

Figure 2. Loads applied over the lumbar L5.

\section{Results}

To determine changes on the mechanical properties of the vertebra, we extracted the stiffness matrix of the domain generated with the mapped non-homogeneous properties. The sparse matrices are compared in terms of their eigenvalues and $L_{2}$-norms. We evaluated the six largest eigenvalues for the two models and compare their percent difference, Table 1. We observe percent differences up to $13,43 \%$ for the second eigenvalue. The $L_{2}$-norm for the CAT from 2009 was $5.08 \mathrm{E}+04$ and for 2014 was $4.68 \mathrm{E}+04$, for a percent difference of $7,92 \%$.

Table 1. Eigenvalues for the stiffness matrix for CAT models from 2009 and 2014.

\begin{tabular}{ccc}
\hline $\mathbf{2 0 0 9}$ & $\mathbf{2 0 1 4}$ & \% difference \\
\hline 50810,21 & 46783,04 & $-8,61$ \\
48967,56 & 43168,24 & $-13,43$ \\
44181,39 & 41838,73 & $-5,60$ \\
42713,13 & 41740,76 & $-2,33$ \\
42264,10 & 40350,57 & $-4,74$ \\
40127,65 & 39693,13 & $-1,09$ \\
\hline
\end{tabular}

To verify changes in geometry and occurrence of metastasis, stress and strain fields were analysed. Different test points (Figs. 3, 4) were evaluated in both models to find possible stress concentrators that could arise because of segmentation errors or because of bone degradation due to metastasis. Also, density decrease because part of a normal ageing process, after age 35, mass bone losing will be between $0,3 \%$ to $0,5 \%$ per year [21]. Regarding this, there is a zone were density could have decreased dramatically, as shows Table 2 , on the second point tested a stress variation of $159 \%$ was found, which could be associated with a change in geometry due to mass bone loss or a degradation 
of mineral bone density.

Table 2. Equivalent stress on different test points.

\begin{tabular}{cccc}
\hline $\begin{array}{c}\text { Equivalent } \\
\text { stress 2009 } \\
{[\mathbf{M P a}]}\end{array}$ & $\begin{array}{c}\text { Equivalent } \\
\text { stress 2014 } \\
{[\mathbf{M P a}]}\end{array}$ & $\begin{array}{c}\text { Location (x, y, z) } \\
{[\mathbf{m}]}\end{array}$ & \% difference \\
\hline 0,57 & 0,57 & $0.006129,0.021090,-0.455290$ & 0,12 \\
0,63 & 1,63 & $0.003925,0.076280,-0.441867$ & 159,47 \\
1,45 & 1,43 & $-0.035230,0.041480,-0.437857$ & 1,08 \\
1,34 & 1,32 & $0.045381,0.039486,-0.434435$ & 1,46 \\
6,54 & 5,92 & $-0.016158,0.034375,-0.440238$ & 9,41 \\
7,56 & 7,04 & $0.026612,0.037148,-0.439232$ & 6,97 \\
\hline
\end{tabular}

Figs. 3 and 4 show changes in strain distribution between the two vertebrae, where the second test point, highlighted in red, is located where stress increases. This zone is called spinous process, and agrees with the clinical assessment for metastasis in that area. This is not an area where metastasis commonly begins, metastatic lesions had been found mostly in the vertebral frontal zone (body) [22]. Strain fields shows significant changes, the location of critical points changed and the distribution, although similar in both cases, shows an increase of the strain values from 5,1E-3 to 5,8E-3.

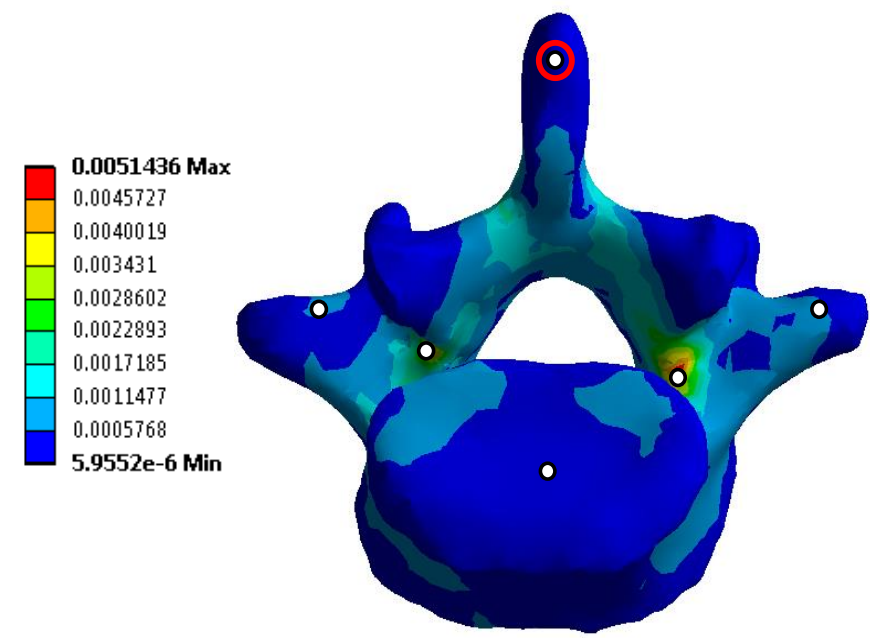

Figure 3. Equivalent strain field with test points for vertebra from 2009.

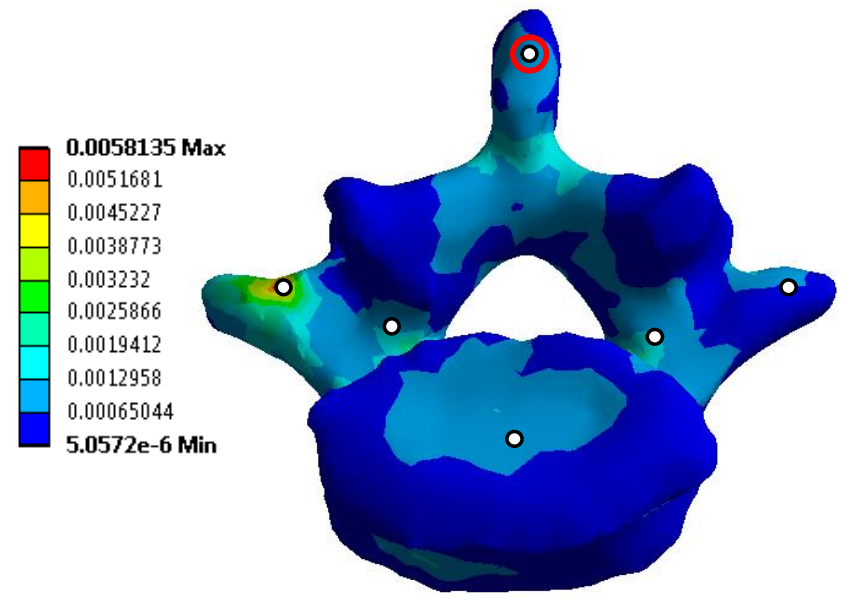

Figure 4. Equivalent strain field with test points for vertebra from 2014. 
To verify these critical points where a metastatic lesion had occurred, the initial models are evaluated. We measure bone mineral density in different slices of the critical points. Where strain changes a density loss of $15 \%$ is found. For the spinous process, where a critical increase of stress was found, the loss of density was $25 \%$. Density measures at random points indicate that the whole vertebra suffered metastasis. This is the most typical case, diagnosed in the $61 \%$ of the patients with prostate cancer [22].

\section{Conclusions}

A methodology to evaluate metastasis due to prostate cancer on lumbar vertebrae was presented. Using 3D models and finite element analysis, we can evaluate the mechanical response of the model and detect changes on bone structure. CAT images are used to create reliable models for such analysis, however, a limited range of slice thickness must be used for this purpose [23]. A model with nonhomogeneous properties was implemented, each element of the mesh had a mean density and strength, and a static analysis with boundary conditions associated to typical loads was developed. Results showed a vertebra with a degradation of its mechanical properties on the whole domain, this kind of lesions are the most typical due to prostate cancer.

\section{References}

[1] M. W. Layton, S. A. Goldstein, R. W. Goulet, L. A. Feldkamp, D. J. Kubinski, and G. G. Bole, "Examination of subchondral bone architecture in experimental osteoarthritis by microscopic computed axial tomography," Arthritis Rheum., vol. 31, no. 11, pp. 1400-1405, Nov. 1988.

[2] E. Avrahami, R. Tadmor, O. Dally, and H. Hadar, "Early MR Demonstration of Spinal Metastases in Patients with Normal Radiographs and CT and Radionuclide Bone Scans," J. Comput. Assist. Tomogr., vol. 13, no. 4, pp. 598-602, Jul. 1989.

[3] S. Schievano et al., "Percutaneous Pulmonary Valve Implantation Based on Rapid Prototyping of Right Ventricular Outflow Tract and Pulmonary Trunk from MR Data," Radiology, vol. 242, no. 2, pp. 490-497, 2007.

[4] F. Valencia, C. Mejía, and V. Erazo, "Desarrollo de una prótesis de rodilla para amputaciones transfemorales usando herramientas computacionales," Rev. UIS Ing., vol. 16, no. 2, pp. 23-34, 2017.

[5] W. C. C. Lee, M. Zhang, X. Jia, and J. T. M. Cheung, "Finite element modeling of the contact interface between trans-tibial residual limb and prosthetic socket," Med. Eng. Phys., vol. 26, no. 8, pp. 655-662, 2004.

[6] E. Nadal Soriano, M. J. Rupérez, S. Martínez Sanchis, C. Monserrat Aranda, M. Tur, and F. J. Fuenmayor, "Evaluación basada en el método del gradiente de las propiedades elásticas de tejidos humanos in vivo," Rev. UIS Ing., vol. 16, no. 1, pp. 15-22, Oct. 2107.

[7] D. Vanel, J. Bittoun, and A. Tardivon, "MRI of bone metastases," Eur. Radiol., vol. 8, no. 8, pp. 1345-1351, Sep. 1998.

[8] J. P. Karr, "Prostate Cancer in the United States and Japan," in Prostate Cancer and Bone Metastasis. Advances in Experimental Medicine and Biology, vol 324, J. P. Karr and H. Yamanaka, Eds. Boston, MA: Springer, 1992, pp. 17-28.

[9] J. Schaberg and B. J. Gainor, "A Profile of Metastatic Carcinoma of the Spine," Spine (Phila. Pa. 1976)., vol. 10, no. 1, pp. 19-20, Jan. 1985.

[10] G. R. Mundy, "Metastasis to bone: Causes, consequences and therapeutic opportunities," Nat. Rev. Cancer, vol. 2, no. 8, pp. 584-593, 2002.

[11] H. E. Daldrup-Link et al., "Whole-Body MR Imaging for Detection of Bone Metastases in 
Children and Young Adults," Am. J. Roentgenol., vol. 177, no. 1, pp. 229-236, 2001.

[12] F. E. Lecouvet et al., "Magnetic resonance imaging of the axial skeleton for detecting bone metastases in patients with high-risk prostate cancer: Diagnostic and cost-effectiveness and comparison with current detection strategies," J. Clin. Oncol., vol. 25, no. 22, pp. 32813287, 2007.

[13] H. Schirrmeister et al., "Early detection and accurate description of extent of metastatic bone disease in breast cancer with fluoride ion and positron emission tomography," J. Clin. Oncol., vol. 17, no. 8, pp. 2381-9, 1999.

[14] A. M. Pham, A. A. Rafii, M. C. Metzger, A. Jamali, and E. B. Strong, "Computer modeling and intraoperative navigation in maxillofacial surgery," Otolaryngol. - Head Neck Surg., vol. 137, no. 4, pp. 624-631, 2007.

[15] D. J. Halazonetis, "From 2-dimensional cephalograms to 3-dimensional computed tomography scans," American Journal of Orthodontics and Dentofacial Orthopedics, vol. 127, no. 5. pp. 627-637, 2005.

[16] J. Y. Rho, M. C. Hobatho, and R. B. Ashman, "Relations of mechanical properties to density and CT numbers in human bone," Med. Eng. Phys., vol. 17, no. 5, pp. 347-355, Jul. 1995.

[17] J. H. Keyak, J. M. Meagher, H. B. Skinner, and C. D. Mote, "Automated three-dimensional finite element modelling of bone: a new method," J. Biomed. Eng., vol. 12, no. 5, pp. 389397, Sep. 1990.

[18] E. Schileo, F. Taddei, A. Malandrino, L. Cristofolini, and M. Viceconti, "Subject-specific finite element models can accurately predict strain levels in long bones," J. Biomech., vol. 40, no. 13, pp. 2982-2989, 2007.

[19] V. K. Goel, W. Kong, J. S. Han, J. N. Weinstein, and L. G. Gilbertson, “A Combined Finite Element and Optimization Investigation of Lumbar Spine Mechanics With and Without Muscles," Spine (Phila. Pa. 1976)., vol. 18, no. 11, pp. 1531-1541, Sep. 1993.

[20] H. G. Sánchez Acevedo, J. Uscátegui, and S. Gómez, "Metodología para la detección de fallas en una estructura entramada metálica empleando las técnicas de análisis modal y PSO," Rev. UIS Ing., vol. 16, no. 2, pp. 43-50, 2017.

[21] J. D. Tobin, K. M. Fox, M. L. Cejku, T. A. Roy, R. S. Epstein, and C. C. Plato, "Bone density changes in normal men: a 4-19 year longitudinal study," J. Bone Miner. Res., vol. 8, no. suppl 1, p. S142, 1993.

[22] T. Suzuki, T. Shimizu, K. Kurokawa, H. Jimbo, J. Sato, and H. Yamanaka, "Pattern of prostate cancer metastasis to the vertebral column.," Prostate, vol. 25, no. 3, pp. 141-146, 1994.

[23] J. M. Ford and S. J. Decker, "Computed tomography slice thickness and its effects on threedimensional reconstruction of anatomical structures," J. Forensic Radiol. Imaging, vol. 4, pp. 43-46, Mar. 2016. 